\title{
Small mammal responses to moose supplementary winter feeding
}

\author{
Simen Pedersen • Karen M. Mathisen • Lucrezia Gorini • \\ Harry P. Andreassen • Eivin Røskaft • Christina Skarpe
}

Received: 24 September 2013 / Revised: 8 January 2014 / Accepted: 18 March 2014 / Published online: 28 March 2014

(C) The Author(s) 2014. This article is published with open access at Springerlink.com

\begin{abstract}
Supplementary feeding of wild large herbivores is a widespread practice in North America and Europe. The presence of feeding stations may have ecological consequences through changes to animal distributions, patterns of herbivory and a net nutrient input into the ecosystem. In Fennoscandia, supplementary feeding of moose in winter (Alces alces) is increasing. Although it has been shown to affect bird communities, its effects on small mammal communities were unknown. Here, we studied the effects of moose supplementary feeding stations on plants and on abundance, reproduction, and biomass of small mammals in years with low and high vole abundance. We sampled small mammals with snap traps and conducted surveys of the field layer vegetation, at varying distances from moose supplemental feeding stations. Due to the vegetation changes induced by feeding stations, abundance of common shrews (Sorex araneus) and Microtus voles were positively affected by long-term moose winter feeding, while bank voles (Myodes glareolus) were not affected. Moose feeding stations did not affect reproduction, individual body mass, or the total biomass of small mammals. Moose winter-feeding stations have impacts on nontarget species,
\end{abstract}

\section{Communicated by C. Gortázar}

S. Pedersen $(\bowtie) \cdot$ K. M. Mathisen • L. Gorini • H. P. Andreassen • C. Skarpe

Department of Forestry and Wildlife Management, Faculty of Applied Ecology and Agricultural Sciences, Hedmark University College, Evenstad, NO-2480 Koppang, Norway

e-mail: simen.pedersen@hihm.no

S. Pedersen · E. Røskaft

Department of Biology, Faculty of Natural Sciences and Technology,

Norwegian University of Science and Technology,

NO-7491 Trondheim, Norway

L. Gorini

Norwegian Institute for Nature Research,

NO-7485 Trondheim, Norway providing islands of preferred grass and forb habitat for Microtus spp. and common shrews, allowing them to penetrate into a matrix of less preferred forest habitat.

Keywords Bank vole $\cdot$ Browsing $\cdot$ Cervid $\cdot$ Microtus spp Shrew $\cdot$ Supplementary feeding

\section{Introduction}

Supplementary feeding of large herbivores is a widespread practice in North America and Europe (Putman and Staines 2004). Goals of feeding include divisionary feeding to reduce damage to cultivated or natural vegetation and to reduce vehicle collisions (Gundersen et al. 2004; van Beest et al. 2010a), and supplementary feeding to improve the quality of trophy animals or to sustain higher populations for hunting (Rodriguez-Hidalgo et al. 2010; Putman and Staines 2004). The presence of feeding stations may have ecological consequences due to the net input of biomass into the ecosystem. Since most of the supplementary food is consumed, effects on the vegetation are mainly expected to be mediated through the enhanced nutrient input from faeces and urine of large herbivores using the feeding stations, as well as from intense herbivory of natural vegetation (Gundersen et al. 2004; van Beest et al. 2010a). The high local density of large herbivores at feeding stations can have consequences for the vegetation composition and structure surrounding the stations (van Beest et al. 2010a). Similar changes have been observed around artificial waterholes (Andrew 1988; Brits et al. 2002), although in the latter case no biomass is added to the ecosystem.

In Fennoscandia, moose (Alces alces) populations have remained high after an initial dramatic increase during the 1970s and 1980s. During the past two decades, there has been increased use of diversionary supplementary winter feeding to mitigate moose damage to young forest and traffic accidents, 
whilst sustaining a high population density for hunting. The practice of supplementary feeding is growing as new winterfeeding areas are established (van Beest et al. 2010b), in addition, moose have increased their use of feeding stations over time in existing winter-feeding areas (van Beest et al. 2010a). As moose using feeding stations continue to browse on natural forage, this causes a high browsing intensity around feeding stations, as well as a high nutrient input through dung, urine, and silage residues (Mathisen and Skarpe 2011; Mathisen et al. 2011; Pedersen et al. 2007). High browsing opens up the canopy and increases light availability, which together with increased nutrient availability may lead to a change in the field layer vegetation from dwarf shrubdominated plant communities to grass-dominated communities (Mathisen et al. 2010). Seed input from graminoid silage residues may also enhance the transition from dwarf shrubs to grass-dominated vegetation (Mathisen and Skarpe 2011). Vegetation changes affect bird abundance and species composition (Mathisen and Skarpe 2011) and reproduction (Mathisen et al. 2011; Pedersen et al. 2007) but may impact other communities as well. While birds are affected by changes in the canopy cover (Mathisen et al. 2011; Pedersen et al. 2007), we may expect small mammals to be affected by the habitat transformation of the field layer from dwarf shrubs to grass and forb vegetation (Mathisen et al. 2010) and concomitant changes in insect fauna (Suominen et al. 1999; Suominen et al. 2008).

Several studies have investigated the effects of large herbivore densities on small mammals, and most of these report negative effects (Keesing and Crawford 2001; Keesing 1998; Johnston and Anthony 2008; Saetnan and Skarpe 2006; Buesching et al. 2011). However, there are few studies investigating effects of supplementary feeding of large herbivores on small mammals (but see Moseley et al. 2011). So far, no studies have investigated the consequences of moose winter-feeding stations (hereafter: feeding stations) on small mammals. These species play a key role in the dynamics of the boreal forest ecosystem both as prey and as primary consumers (Strann et al. 2002; Ims et al. 2008; Korpimäki and Norrdahl 1989). If feeding stations for moose alter the abundance and composition of the small mammal community, it could have regional effects on other components of the boreal forest ecosystem.

Bank voles (Myodes glareolus) inhabit dwarf shrub habitat, especially bilberry (Vaccinium myrtillus) (e.g., Selås 2006), whereas Microtus spp. voles are associated with grasses and forbs (e.g. Panzacchi et al. 2010). Common shrews (Sorex araneus) prefer areas of high primary productivity that support a high abundance of their invertebrate prey (Hanski and Kaikusalo 1989; Saarikko 1989). Home range size varies from 800 to $1,500 \mathrm{~m}^{2}$ for bank voles (Bondrup-Nielsen and Karlsson 1985; Eccard and Ylönen 2007) and from 300 to $1,800 \mathrm{~m}^{2}$ for Microtus spp. (Andreassen et al. 1996; Bondrup-Nielsen and
Karlsson 1985), while the home ranges of common shrew vary from 500 to 2,400 $\mathrm{m}^{2}$ (Kollars 1995; Wang and Grimm 2007). Thus, all these small mammals could potentially be affected by moose-feeding stations as the habitat transformations associated with feeding stations occur at a scale larger than small mammal home ranges ( $\sim 5,000-8,000 \mathrm{~m}^{2}$, S. Pedersen pers. obs.).

Microtus spp. are larger than bank voles, but tend to have smaller territories (Bondrup-Nielsen and Karlsson 1985) and a higher population growth capacity (Ylönen et al. 1988). Shrews and Microtus spp. may be expected to benefit from the vegetation changes induced by feeding stations more than bank voles. Consequently, we may expect a higher biomass of small mammals around feeding stations than of in other parts of the forest. Furthermore, we may expect that the vegetation changes induced by feeding stations are better able to support voles and shrews during winter, creating hotspots with high winter survival. Feeding stations may therefore provide a relatively constant availability of prey for the predator fauna, which dampen the amplitude of multiannual vole cycles (Krebs 1996; Stenseth et al. 1996) around feeding stations. Moose only use the feeding stations in winter, but effects on the vegetation last throughout the year and could have lag effects during the reproductive period of the voles during summer. Our goals were to investigate effects feeding stations have on small mammal species composition, reproduction, and abundance. We surveyed field layer vegetation and trapped small mammals using snap-traps at three distances from feeding stations in a year with low vole abundance and a year with high vole abundance. We chose three different distances from feeding stations as the local effects of moose activity decrease with distance from the feeding stations (Mathisen et al. 2011; Pedersen et al. 2007).

We predicted (1) graminivorous vole species such as Microtus spp. would have higher abundances in the grassdominated vegetation close to the feeding stations compared to intermediate and far distances; (2) bank voles that are associated with dwarf shrub habitat would have higher abundances at distances away from feeding stations; (3) a positive effect of feeding stations on the abundance of common shrew, since this species is a generalist insectivore that prefers areas of high habitat productivity; (4) if feeding stations stabilizes small mammal populations, we also expected higher total small mammal biomass and less variation in densities between the peak and low year, near feeding stations compared to intermediate and far distances. We predicted that the different species would (5) be in better condition (i.e. increased body mass) and (6) have better reproductive performance in their preferred habitats in accordance with the theory of ideal despotic distribution (Fretwell 1972). Specifically, we predicted that bank voles would have lower body mass and produce fewer offspring close to feeding stations compared to areas away from the feeding stations, whereas the opposite should be the case for the Microtus species and common shrews. 


\section{Methods}

Study area

We conducted the field study at two sites (Imsdalen and Koppangskjølen) within Stor-Elvdal municipality, in Hedmark County, SE Norway $\left(\sim 61^{\circ} \mathrm{N}, 11^{\circ} \mathrm{E}\right)$ (Pedersen 2011). The study area was situated between 300 and $840 \mathrm{~m}$ a.s.l. in the middle and northern boreal zones (Moen et al. 1999). The topography was dominated by the Glomma river main valley running from north to south, with side valleys feeding into the main valley. The forest was dominated by pure or mixed stands of Scots pine (Pinus sylvestris), Norway spruce (Picea abies), and downy birch (Betula pubescens), interspersed with species such as silver birch (Betula pendula), grey alder (Alnus incana), rowan (Sorbus aucuparia), aspen (Populus tremula), and willows (Salix spp.). Aspen, rowan, and willows are the preferred browse species for moose, while Scots pine and birches are the staple food for moose (e.g. Månsson et al. 2007). The field layer vegetation was dominated by dwarf shrubs such as bilberry which is one of the most common dwarf shrub forage species for moose (Cederlund et al. 1980), as well as cowberry (Vaccinium vitis-idaea). The climate was continental with a mean January and July temperature of $-10.8{ }^{\circ} \mathrm{C}$ and $14.0^{\circ} \mathrm{C}$, respectively, and a mean annual precipitation of $795 \mathrm{~mm}$ (Evenstad weather station in main valley NMI 2011 [www.eklima.met.no]).

\section{Moose supplementary feeding}

The moose population in the study system was partly migratory. Moose from the surrounding mountainous areas migrate to lower elevations in the valley bottom of the main and side valleys as snow accumulates in early winter. The overall moose winter density in the municipality varied between 1.1 and 3.4 moose per $\mathrm{km}^{2}$ (Gundersen et al. 2004; Storaas et al. 2005). Members of the local landowner association have been feeding moose with bales of silage during winter since 1990 (Gundersen et al. 2004; Storaas et al. 2005). The locations of the feeding stations were determined by the landowners, e.g. depending on accessibility during winter, proximity to regenerating forest stands, and proximity to the main valley. The bales supplied at the feeding stations consisted of ensilaged mixed graminoids and weighed approximately $600 \mathrm{~kg}$ wet weight. The food is provided ad libitum for up to 6 months a year when snow cover is deep enough to prevent moose from utilizing vegetation in the summer feeding areas. The practice of supplementary feeding has increased dramatically from approximately 150 ton across 44 feeding stations in the winter $1997 / 1998$ to approximately 1,700 ton across 157 feeding stations in the winter 2007/2008 (van Beest et al. 2010a). Feeding stations attract high numbers of moose, causing the effective density to increase by orders of magnitude compared to surrounding areas.
Previous work in the present study system showed a strong positive relationship between the number of moose faecal pellet groups, browsing pressure, and proximity to feeding stations (Pedersen et al. 2007; Mathisen et al. 2011; Mathisen and Skarpe 2011), thus we did not measure these variables.

\section{Study design}

As the effects of feeding stations on the vegetation gradually decrease with increasing distance, we established study plots at three distances from moose feeding stations (feeding station, 0-30 m; intermediate, $150-400 \mathrm{~m}$, and far, 900$1,500 \mathrm{~m})$. These distance classes were characterized by a high nutrient input from silage, dung and urine, as well as high browsing pressure at feeding stations; low nutrient input but high browsing pressure at intermediate distances; lower nutrient input and browsing pressure at far distances (van Beest et al. 2010a). We used a subset of the plots surveyed by Mathisen et al. (2011). In each plot, we trapped small mammals and surveyed the vegetation. To minimize variation among plots, we focused on mixed conifer-birch forest in Norwegian forestry cutting class 2 (trees up to $8 \mathrm{~m}$ ) or 3 (trees above $8 \mathrm{~m}$ but not mature for final felling), with a field layer dominated by bilberry or cowberry (Moen et al. 1999). As feeding stations altered the field layer vegetation, we determined the vegetation type outside the immediately affected areas to identify the field layer vegetation type prior to feeding station establishment. Our criteria yielded a balanced design of 11 feeding station (FS), 11 intermediate (INT), and 11 far (FAR) plots. Plots were selected systematically and not designated by random allocation; our study design is quasiexperimental rather than strictly experimental. Such studies are highly structured observational studies, with some nonrandom treatments (Shadish et al. 2002).

\section{Field procedures}

\section{Small mammal trapping}

In the early fall (early September) of 2008 and 2010, we conducted snap-trapping of small mammals using "Rapp" snap-traps (Nordenfjeldske Børstefabrikk, Surnadal, Norway). We did not conduct any trapping in 2009 due to low vole population densities in the area (Gorini et al. 2011). In 2008, we trapped at all 33 plots except one plot at the far distance where there was a radio-marked least weasel (Mustela nivalis) (from to another project). In 2010, just before onset of the trapping session, one plot was clear-felled, reducing the number of plots at feeding stations to 10 . Traps were baited with carrots dipped in peanut butter and placed in grids of four columns (AD) and four rows (1-4), spaced $15 \mathrm{~m}$ apart and placed under the field layer vegetation. In 2010, we reduced trapping effort to 12 traps per plot (excluding the fourth row). We checked the traps 
every morning for four consecutive nights. Traps were re-baited and re-armed if necessary. Animals were placed in individual bags marked with the plot number for later processing in the lab.

\section{Vegetation survey}

We surveyed vegetation in late July and early August 2010 at the plots where we trapped small mammals that year. In each plot, we conducted the survey at four trap locations (A1, C1, A3, and C3 [see above]). First, we recorded the cover of field layer vegetation in four $1-\mathrm{m}^{2}$ quadrats, placed $2 \mathrm{~m}$ from the trap in each of the cardinal directions. Here, we recorded the percentage cover of raspberry (Rubus idaeus), fireweed (Chamerion angustifolium), stinging nettle (Urtica spp.), cowberry, bilberry, and the plant groups, moss, lichen, grass, other forbs, and other dwarf shrubs. We recorded percent cover visible from above summing up to $100 \%$. Since bilberry is an important food plant for bank voles (e.g. Selås 2006), we measured the height of the four bilberry shoots (if present) closest to the corners of the plot. As a measure of the visibility to potential vole predators, we placed a 1-m Robel pole with 10 alternating white and red $10-\mathrm{cm}$ sections horizontally on the ground beneath the field layer vegetation. Standing at the base of the stick viewing from 1-m height, we recorded visual obstruction (i.e. how many of the 10 sections had at least $50 \%$ of the section visible). We did this in four directions centered on the trap and perpendicular to each other, avoiding vegetation trampled by the observer. We estimated forest composition in 2007 as the percentage canopy cover of the different tree species above and below $3 \mathrm{~m}$ in height, in a circle with radius $10 \mathrm{~m}$ around the center of the plot (Mathisen et al. 2011).

\section{Lab procedures}

We processed all trapped animals in the lab. They were weighed to the nearest $0.001 \mathrm{~g}$. We used the shape of the molars to distinguish between root voles (Microtus oeconomus) and field voles (Microtus agrestis) (Wollebæk 1947). Then, we cut open the abdomen and determined the sex and age of the animals from inspection of the gonads. In voles, the uterus of juvenile females is thin and transparent, while the uterine walls become thicker and whitish at maturation. For adult females, we examined the uterus for placental scars and embryos (Alibhai 1982) and used the sum of scars and embryos as a measure of reproductive output. For males, we checked for development of the epididymis tubuli and we used this together with size of testicles as a measure of sexual maturity. We did not determine sex and age of shrews.

Statistical methods

All analyses were conducted using the program R Version 2.13.0 (www.r-project.org) and associated packages. For all analyses, we tested for an effect of distance to feeding station as a categorical variable (FS, INT, FAR) and included an interaction with year for abundance (number of captures), body mass, reproduction, and small mammal biomass, since the density of voles is known to vary greatly between years (Ims et al. 2008; Hörnfeldt 2004). However, we did not test for a year effect for common shrews as they were only caught in 2010. Since the productivity and spatial location differed between the two areas Imsdalen and Koppangskjølen, we included area as a random intercept term if it improved the model significantly. We selected model type and nesting structure based on Akaike's Information Criterion corrected for small sample size (AICc) values. When the model type and nesting structure was given, we compared models with different explanatory variables based on Likelihood ratios for linear mixed effects models (LME), $F$ tests for generalized linear models (GLM), $\chi^{2}$ tests for generalized linear mixed effects models (GLMM) and $t$ tests for analysis of variance (ANOVA) (Zuur et al. 2009). We grouped root voles and field voles as a genus (Microtus spp.) because number of captures was too sparse to run proper analyses for each species. In 2010 , we excluded 16 voles that were too damaged by scavengers for proper species identification. We also excluded 18 voles that were partly consumed by scavengers from the analysis of body mass. In 2008, we captured only two adult Microtus spp. females, while in 2010, three females had missing parts of the uterus due to scavengers; these five females were excluded from analysis on reproduction.

Firstly, we tested whether there were any differences in the visibility index, field layer vegetation composition, and tree species composition depending on distance from moose feeding stations. The cover of rowan, aspen, alder, and willows was low; hence, we grouped them together (RAAW). We pooled the variables from the four sampling quadrats of each plot and tested whether the vegetation variables varied among distance classes with ANOVAs. Vegetation percentage cover and visibility proportion data were arcsine square root transformed. Secondly, we analysed the small mammal abundance (captures per trap night to account for varying trapping intensity between the years), body mass, reproduction, biomass, and difference in biomass between 2008 and 2010 using GLM, GLMM, and LME, depending on the distribution and whether a mixed effects model was appropriate. We corrected for overdispersion if detected in GLMMs by including a plot level random intercept term. We tested whether abundance (number of captures per trap night) of common shrew, bank vole and Microtus spp. could be explained by distance and year (for bank voles and Microtus spp. only) with a binomial error structure. Then, we tested whether body mass of shrews and male voles (to avoid variation caused by pregnant vole females) could be explained by distance and year, with plots nested within area as random intercept terms to avoid pseudoreplication, and for voles we included age (adult or juvenile) as a covariable. Then, we tested 
whether the total sum of offspring produced by adult bank vole and Microtus spp. females were affected by distance and, in the case of bank voles, year. Again, plots were nested within area to control for pseudoreplication. In addition, we tested whether distance from feeding station explained biomass per plot and trap night. For those plots where we trapped in both years, we tested whether there was any effect of distance on the difference in small mammal biomass between 2008 and 2010. First, we tested all small mammal species together and then only voles, excluding common shrews due to mammalian predators having a distaste for shrews (Korpimäki and Norrdahl 1989). Biomass per trap night was square root transformed to achieve normality. Last, we tested whether the difference in abundance (number of captures of all species) between years varied with distance.

\section{Results}

Vegetation composition varied between the three distance classes (Table 1), with field layer vegetation in general being more affected by distance to feeding stations than the tree layer. The percentage cover of nettles, fireweed, raspberry, and grasses was higher at feeding stations compared to intermediate and far distances (Table 1). Percentage cover of moss and the visibility index score was lower at feeding stations compared to the other two distance categories (Table 1), while canopy cover of birch $>3 \mathrm{~m}$ was the highest at intermediate distances (Table 1).

We trapped a total of 465 small mammals (346 bank voles, 51 Microtus spp., 51 common shrews, 16 unidentified voles, and 1 wood lemming [Myopus schisticolor]) over the 2 years (76 in 2008 and 389 in 2010). We captured more Microtus spp. per trap night at feeding stations compared to the other two distances $\left(F_{2}=6.35, P=0.003\right.$, Fig. 1a). There was also a higher abundance of Microtus spp. in 2010 compared to $2008\left(F_{1}=9.02, P=0.004\right.$, Fig. 1a). Bank vole abundance showed a nonsignificant positive trend with increasing distance to feeding stations $\left(\chi_{2}^{2}=3.67, P=\right.$ 0.160 , Fig. 1b), but we captured more bank voles per trap night in 2010 compared to $2008\left(\chi_{1}^{2}=223.28, P<0.001\right.$, Fig. $\left.1 b\right)$. We only caught shrews in 2010, and abundance decreased with distance to feeding station $\left(\chi_{2}{ }^{2}=13.67, P=0.001\right.$, Fig. $\left.1 \mathrm{c}\right)$.

Bank vole males were on average $3.20( \pm \mathrm{SE} 0.50)$ grams heavier in $2010(24.71 \mathrm{~g})$ than in $2008(21.51 \mathrm{~g})\left(L_{1}=36.23\right.$, $P<0.001)$, but we found no effect of distance to feeding stations on body mass $\left(L_{2}=1.69, P=0.428\right)$. For Microtus

Table 1 Effects $( \pm \mathrm{SE})$ of distance to moose supplementary feeding stations on field layer vegetation and tree layer vegetation. For bilberry height, we assumed normal errors, while the rest of the variables were

arcsine square root transformed. Area was included as a random intercept term if it improved the fit of the model significantly

\begin{tabular}{|c|c|c|c|c|c|}
\hline Variable & FS & INT & FAR & $F(d f)$ & $P$ \\
\hline Bilberry height & $13.11( \pm 0.76)$ & $15.58( \pm 0.69)$ & $14.06( \pm 0.69)$ & $3.03(2,28)$ & 0.064 \\
\hline Visibility & $0.63( \pm 0.03)$ & $0.73( \pm 0.03)$ & $0.72( \pm 0.03)$ & $3.78(2,29)$ & 0.026 \\
\hline Moss & $0.32( \pm 0.04)$ & $0.54( \pm 0.04)$ & $0.55( \pm 0.04)$ & $12.15(2,29)$ & $<0.001$ \\
\hline Lichen & $0.17( \pm 0.04)$ & $0.20( \pm 0.04)$ & $0.20( \pm 0.04)$ & $0.22(2,29)$ & 0.801 \\
\hline Grasses & $0.46( \pm 0.04)$ & $0.26( \pm 0.04)$ & $0.18( \pm 0.04)$ & $12.46(2,29)$ & $<0.001$ \\
\hline Fireweed & $0.14( \pm 0.03)$ & $0.02( \pm 0.02)$ & $0.02( \pm 0.02)$ & $7.96(2,29)$ & 0.002 \\
\hline Nettles & $0.14( \pm 0.04)$ & $<0.01( \pm 0.03)$ & $<0.01( \pm 0.03)$ & $5.27(2,29)$ & 0.011 \\
\hline Raspberry & $0.11( \pm 0.03)$ & $0.01( \pm 0.03)$ & $0.01( \pm 0.03)$ & $3.97(2,29)$ & 0.030 \\
\hline Other forbs & $0.33( \pm 0.05)$ & $0.21( \pm 0.04)$ & $0.17( \pm 0.04)$ & $3.17(2,29)$ & 0.057 \\
\hline Cowberry & $0.27( \pm 0.03)$ & $0.36( \pm 0.03)$ & $0.35( \pm 0.03)$ & $2.49(2,29)$ & 0.100 \\
\hline Bilberry & $0.26( \pm 0.04)$ & $0.36( \pm 0.04)$ & $0.39( \pm 0.04)$ & $2.50(2,29)$ & 0.100 \\
\hline Other dwarf shrubs & $0.36( \pm 0.05)$ & $0.34( \pm 0.05)$ & $0.44( \pm 0.05)$ & $1.81(2,27)$ & 0.184 \\
\hline Birch $>3 \mathrm{~m}$ & $0.30( \pm 0.04)$ & $0.46( \pm 0.04)$ & $0.31( \pm 0.04)$ & $5.07(2,29)$ & 0.013 \\
\hline Birch $<3 \mathrm{~m}$ & $0.31( \pm 0.03)$ & $0.28( \pm 0.03)$ & $0.30( \pm 0.03)$ & $0.20(2,29)$ & 0.819 \\
\hline Pine $>3 \mathrm{~m}$ & $0.14( \pm 0.06)$ & $0.17( \pm 0.06)$ & $0.22( \pm 0.06)$ & $0.46(2,29)$ & 0.633 \\
\hline Pine $<3 \mathrm{~m}$ & $0.04( \pm 0.02)$ & $0.05( \pm 0.02)$ & $0.09( \pm 0.02)$ & $1.74(2,29)$ & 0.194 \\
\hline Spruce $>3 \mathrm{~m}$ & $0.24( \pm 0.05)$ & $0.24( \pm 0.05)$ & $0.30( \pm 0.05)$ & $0.58(2,29)$ & 0.568 \\
\hline Spruce $<3 \mathrm{~m}$ & $0.19( \pm 0.03)$ & $0.16( \pm 0.03)$ & $0.19( \pm 0.03)$ & $0.35(2,29)$ & 0.707 \\
\hline RAAW >3 m & $0.02( \pm 0.01)$ & $<0.01( \pm 0.01)$ & $<0.01( \pm 0.01)$ & $1.11(2,29)$ & 0.344 \\
\hline RAAW $<3 \mathrm{~m}$ & $0.10( \pm 0.03)$ & $0.11( \pm 0.03)$ & $0.09( \pm 0.03)$ & $0.23(2,29)$ & 0.794 \\
\hline
\end{tabular}

FS moose feeding stations $(<30 \mathrm{~m}), I N T$ intermediate distances $(150-400 \mathrm{~m})$, and $F A R$ far distances $(900-1,500 \mathrm{~m}) . R A A W$ includes rowan, aspen, alder, and willow 
spp. males, we did not find any effect of distance to feeding stations $\left(L_{1}=0.14, P=0.707\right)$ or year $\left(L_{1}=0.11, P=0.739\right)$ on body mass. Also, body mass of common shrews was unaffected by distance $\left(L_{2}=1.41, P=0.495\right)$.

We did not find any effect of distance $\left(\chi_{2}^{2}=3.10, P=\right.$ $0.212)$ or year $\left(\chi_{1}^{2}=1.12, P=0.291\right)$ on bank vole reproduction (i.e. number of placental scars). Similarly, we found no effect of distance $\left(\chi_{2}{ }^{2}=2.17, P=0.205\right)$ on Microtus spp. reproduction in 2010.

Finally, we tested whether moose-feeding stations supported a higher biomass of small mammals and reduce the variation in biomass between low and high density years. We found no effect of distance on total small mammal biomass $\left(F_{2}=\right.$ $0.11, P=0.895)$ or total vole biomass $\left(F_{1}=0.28, P=0.756\right)$. There was a strong year effect with, on average, $1.42 \mathrm{~g}( \pm \mathrm{SE}$ $0.01)$ more small mammal biomass (including shrews) per trap night in 2010 than in $2008\left(F_{1}=94.26, P<0.001\right)$ and $1.26 \mathrm{~g} \mathrm{(} \pm \mathrm{SE} 0.02)$ more vole biomass (excluding shrews) per trap night in 2010 compared to $2008\left(F_{1}=72.55, P<0.001\right)$. However, we found no effect of distance to feeding station on the difference in biomass between the high and low density years $\left(F_{2}=1.08, P=0.363\right)$ or on the difference in Microtus spp. abundance (number of captures) between years $\left(\chi_{2}^{2}=\right.$ 3.92, $P=0.141)$. Nor was there a difference in year to year variation in bank vole abundance at feeding stations compared to the other two distances $\left(\chi_{2}^{2}=5.05, P=0.080\right)$.

\section{Discussion}

Abundance of Microtus spp. and common shrews showed a positive response to moose supplementary winter-feeding stations, while bank voles were not affected by distance from feeding stations. Responses were most likely caused by the shift in field layer vegetation from dwarf shrub dominated to grass and forb dominated vegetation, mediated by moose-feeding stations (Mathisen et al. 2010; Mathisen and Skarpe 2011).

Vegetation composition varied with distance, as the feeding stations were characterized by lush vegetation with nutrientdemanding plants such as nettles, fireweed, raspberry, and a high percentage of grass cover. On the other hand, moss cover was lower at feeding stations compared to the other two distances, possibly being displaced by more competitive nutrient-demanding plants (Olsson and Kellner 2006). As a consequence of the vegetation changes, with an increase in tall vegetation at the potential expense of the low growth forms, the visibility at the ground is also lower at feeding stations compared to the other distance categories. Hence, increased cover from predators. The only tree species that showed any response to distance from feeding station was birch canopy cover above $3 \mathrm{~m}$, which had the greatest cover at intermediate distances.


Fig. 1 Abundance (number of captures at plots per trap night) of a Microtus spp., b bank voles, and c common shrews ( $\pm 95 \%$ CI) at moose feeding stations ( FS $<30 \mathrm{~m}$ ), intermediate distances (INT 150-400 m) and far distances (FAR 900-1,500 m) from moose-feeding stations. Light blue bars represent FS, blue bars represent INT, while dark blue bars represent FAR distances

Supporting our first and third predictions, abundance of Microtus spp. and common shrews were generally positively affected by feeding stations. Our second prediction was not supported as bank vole abundance was unaffected by feeding stations. The effects on small mammals are probably due to changes in vegetation composition at feeding stations. However, this does not explain the lack of an effect on bank vole abundance. Mathisen et al. (2011) hypothesizes that the density of field layer-dwelling arthropods was higher at feeding stations compared to the other distances. This would be beneficial for shrews that base their habitat selection on invertebrate availability (Wang and Grimm 2007).

In contrast to other studies (e.g. Schmidt et al. 2005), Microtus spp. were positively affected by large herbivore impacts in the current study. This was probably due to feeding stations not being utilized by moose during the summer, in combination with the increased nutrient input from the added silage, dung, and urine (Mathisen et al. 2011; Mathisen and Skarpe 2011; Pedersen et al. 2007), benefitting the Microtus species.

The size of the area close to feeding stations where field layer vegetation is strongly affected $\left(\sim 5,000-8,000 \mathrm{~m}^{2}, \mathrm{~S}\right.$. Pedersen, pers. obs.) is many times larger than the home range 
size of the respective species (Andreassen et al. 1996; Bondrup-Nielsen and Karlsson 1985; Eccard and Ylönen 2007), and can therefore affect density of small mammals. However, contrary to our fourth prediction, we did not find small mammal biomass to be higher at feeding stations. This might be because the positive response of Microtus spp. and common shrew numbers and thereby biomass near feeding stations was offset by a simultaneous (nonsignificant) increase in bank vole numbers and thereby biomass far from feeding stations. Also, contrary to our fourth prediction, we did not detect any lower interannual variation in vole abundance at feeding stations compared to the other two distances. High moose activity at feeding stations and trampling may compress the subnivean space, leaving it less suitable for small mammals during winter. Feeding stations and do not appear to have the potential of to either dampening the amplitude of vole cycles or sustaining a higher density of small mammalian predators. However, sampling over a complete vole cycle is needed to draw firm conclusions on this issue.

Despite an effect on small mammal abundance, we could not trace this effect to differences in individual body mass, rejecting our fifth prediction. Since voles and shrews are territorial, we should expect them to behave in accordance with the ideal despotic distribution, whereby subordinates are forced into marginal habitats where reproduction should also be lower (Fretwell 1972). However, we did not detect lower reproductive output in lower density habitats rejecting our sixth prediction. On the other hand, we cannot rule out the possibility that feeding stations affect immigration or survival after birth. Indeed, either survival after birth or immigration must be higher in the preferred habitats of the respective vole species. Feeding stations are probably important for Microtus spp. and shrews, as they provide islands of preferred habitat allowing them to penetrate into in a matrix of less preferred forest habitat.

The current study was carried out in a system where there is intense browsing and nutrient input from large herbivores in winter while preferred plants are not heavily utilized in another season due to seasonal migration (Mathisen et al. 2011; Mathisen and Skarpe 2011; Pedersen et al. 2007). One might expect to find the same patterns at waterholes where large herbivores are attracted during the dry season causing a high browsing pressure and nutrient input (Andrew 1988; Brits et al. 2002), and where nutrient and light demanding plants may respond to this by increased growth in the rainy season. Similar mechanisms might also be present in seasonal migratory systems where high densities of large herbivores during the vegetation dormancy season browse and deposit nutrients, while low large herbivore densities during the vegetation growth season lead to increased vegetation growth. Seasonal use could create a preferred habitat of small mammal species preferring tall, nutrient rich forb, and grass vegetation, thus increasing their population densities. However, the difference between the waterhole and migratory systems and the current study is that no biomass is added to the former two systems.

Adding biomass to an ecosystem has impacts on the energy flow in the system, and we have shown that supplementary feeding of large herbivores may cause unintended effects on other taxa. By modifying the landscape, albeit on a small scale, moose supplementary winter-feeding stations have an impact on nontarget species. In areas with intensive feeding programs, this may have an impact on the dynamics of small mammal species.

Acknowledgments We appreciate the effort of all students involved in field data collection, especially A. F. Hansen, and C. Körner who also dissected the voles in the lab. We also thank the Stor-Elvdal landowners for allowing us to trap small mammals on their land. We are indebted to E. B. Nilsen for being part of initiating the series of moose-feeding station studies. J. E. Swenson, J.E. Milner, B. K. Sandercock, and two anonymous reviewers provided useful comments on an earlier draft. This study was funded by Hedmark University College.

Ethical standards The practices applied in this study comply with the current laws of Norway.

Conflict of interest We declare that we have no conflicts of interest.

Open Access This article is distributed under the terms of the Creative Commons Attribution License which permits any use, distribution, and reproduction in any medium, provided the original author(s) and the source are credited.

\section{References}

Alibhai SK (1982) Persistence of placental scars in the bank vole, Clethrionomys glareolus. J Zool 197(Jun):300-303

Andreassen HP, Halle S, Ims RA (1996) Optimal width of movement corridors for root voles: not too narrow and not too wide. J Appl Ecol 33:63-70

Andrew MH (1988) Grazing impact in relation to livestock watering points. Trends Ecol Evol 3(12):336-339. doi:10.1016/01695347(88)90090-0

Bondrup-Nielsen S, Karlsson F (1985) Movements and spatial patterns in populations of Clethrionomys species: a review. Ann Zool Fenn 22(3):385-392

Brits J, van Rooyen MW, van Rooyen N (2002) Ecological impact of large herbivores on the woody vegetation at selected watering points on the eastern basaltic soils in the Kruger National Park. Afr J Ecol 40(1):53-60

Buesching CD, Newman C, Jones JT, Macdonald DW (2011) Testing the effects of deer grazing on two woodland rodents, bankvoles and woodmice. Basic Appl Ecol 12(3):207-214

Cederlund G, Ljungqvist H, Markgren G, Stalfelt F (1980) Foods of moose and roe-deer at Grimsö in central Sweden. Results of rumen content analyses. Viltrevy 11:169-244

Eccard JA, Ylönen H (2007) Costs of coexistence along a gradient of competitor densities: an experiment with arvicoline rodents. J Anim Ecol 76(1):65-71

Fretwell SD (1972) Populations in a seasonal environment. Princeton University Press, Princeton

Gorini L, Linnell JDC, Boitani L, Hauptmann U, Odden M, Wegge P, Nilsen EB (2011) Guild composition and habitat use of voles in two 
forest landscapes in south-eastern Norway. Integrative Zoology 6(3):299-310

Gundersen H, Andreassen HP, Storaas T (2004) Supplemental feeding of migratory moose Alces alces: forest damage at two spatial scales. Wildl Biol 10:213-223

Hanski I, Kaikusalo A (1989) Distribution and habitat selection of shrews in Finland. Ann Zool Fenn 26(4):339-348

Hörnfeldt B (2004) Long-term decline in numbers of cyclic voles in boreal Sweden: analysis and presentation of hypotheses. Oikos 107(2):376-392

Ims RA, Henden JA, Killengreen ST (2008) Collapsing population cycles. Trends Ecol Evol 23(2):79-86

Johnston AN, Anthony RG (2008) Small-mammal microhabitat associations and response to grazing in Oregon. J Wildl Manag 72(8):17361746. doi:10.2193/2006-405

Keesing F (1998) Impacts of ungulates on the demography and diversity of small mammals in central Kenya. Oecologia 116(3):381-389

Keesing F, Crawford T (2001) Impacts of density and large mammals on space use by the pouched mouse (Saccostomus mearnsi) in central Kenya. J Trop Ecol 17:465-472

Kollars TM (1995) Home ranges and population-densities of shrews (Soricidae) inhabiting a spruce plantation in Bavaria, Germany. Acta Theriol 40(2):219-222

Korpimäki E, Norrdahl K (1989) Avian and mammalian predators of shrews in Europe: regional differences, between-year and seasonal variation, and mortality due to predation. Ann Zool Fenn 26(4):389-400

Krebs CJ (1996) Population cycles revisited. J Mammal 77(1):8-24. doi: $10.2307 / 1382705$

Månsson J, Kalen C, Kjellander P, Andren H, Smith H (2007) Quantitative estimates of tree species selectivity by moose (Alces alces) in a forest landscape. Scand J For Res 22(5):407-414. doi:10. 1080/02827580701515023

Mathisen KM, Skarpe C (2011) Cascading effects of moose (Alces alces) management on birds. Ecol Res 26(3):563-574

Mathisen KM, Buhtz F, Danell K, Bergstrom R, Skarpe C, Suominen O, Persson IL (2010) Moose density and habitat productivity affects reproduction, growth and species composition in field layer vegetation. J Veg Sci 21(4):705-716

Mathisen KM, Pedersen S, Nilsen EB, Skarpe C (2011) Contrasting responses of two passerine bird species to moose browsing. Eur J Wildl Res 58(3):535-547. doi:10.1007/s10344-011-0601-3

Moen A, Lillethun A, Odland A (1999) National atlas of Norway: vegetation. Norwegian Mapping Authority, Hønefoss

Moseley WA, Cooper SM, Hewitt DG, Fulbright TE, Deyoung CA (2011) Effects of supplemental feeding and density of white-tailed deer on rodents. J Wildl Manag 75(3):675-681

Olsson BA, Kellner O (2006) Long-term effects of nitrogen fertilization on ground vegetation in coniferous forests. For Ecol Manag 237(13):458-470. doi:10.1016/j.foreco.2006.09.068

Panzacchi M, Linnell JDC, Melis C, Odden M, Odden J, Gorini L, Andersen R (2010) Effect of land-use on small mammal abundance and diversity in a forest-farmland mosaic landscape in south-eastern Norway. For Ecol Manag 259(8):1536-1545

Pedersen S (2011) Effects of native and introduced cervids on small mammals and birds. PhD Thesis, Norwegian University of Science and Technology Trondheim. http://www.diva-portal.org/ smash/get/diva2:512518/FULLTEXT02

Pedersen S, Nilsen EB, Andreassen HP (2007) Moose winter browsing affects the breeding success of great tits. Ecoscience 14(4):499-506
Putman RJ, Staines BW (2004) Supplementary winter feeding of wild red deer Cervus elaphus in Europe and North America: justifications, feeding practice and effectiveness. Mammal Rev 34(4):285-306

Rodriguez-Hidalgo P, Gortazar C, Tortosa FS, Rodriguez-Vigal C, Fierro Y, Vicente J (2010) Effects of density, climate, and supplementary forage on body mass and pregnancy rates of female red deer in Spain. Oecologia 164(2):389-398

Saarikko J (1989) Foraging behavior of shrews. Ann Zool Fenn 26(4): 411-423

Saetnan ER, Skarpe C (2006) The effect of ungulate grazing on a small mammal community in southeastern Botswana. Afr Zool 41(1):9-16

Schmidt NM, Olsen H, Bildsoe M, Sluydts V, Leirs H (2005) Effects of grazing intensity on small mammal population ecology in wet meadows. Basic Appl Ecol 6(1):57-66

Selås V (2006) Explaining bank vole cycles in southern Norway 19802004 from bilberry reports 1932-1977 and climate. Oecologia 147(4):625-631

Shadish WR, Cook TD, Campbell DT (2002) Experimental and quasiexperimental designs for generalised causal inference. Houghton Mifflin, Boston

Stenseth NC, Bjornstad ON, Falck W (1996) Is spacing behaviour coupled with predation causing the microtine density cycle? A synthesis of current process-oriented and pattern-oriented studies. Proceedings of the Royal Society of London Series B-Biological Sciences 263(1376):1423-1435. doi:10.1098/rspb.1996.0208

Storaas T, Nicolaysen KB, Gundersen H, Zimmermann B (2005) Project moose-traffic in Stor-Elvdal 2000-2004. How to avoid moosevehicle accidents on roads and railway lines. Hedmark University College, Evenstad

Strann KB, Yoccoz NG, Ims RA (2002) Is the heart of Fennoscandian rodent cycle still beating? A 14-year study of small mammals and Tengmalm's owls in northern Norway. Ecography 25(1):81-87

Suominen O, Danell K, Bergström R (1999) Moose, trees, and groundliving invertebrates: indirect interactions in Swedish pine forests. Oikos 84:215-226

Suominen O, Persson IL, Danell K, Bergstrom R, Pastor J (2008) Impact of simulated moose densities on abundance and richness of vegetation, herbivorous and predatory arthropods along a productivity gradient. Ecography 31(5):636-645. doi:10.1111/j.0906-7590. 2008.05480.x

van Beest FM, Gundersen H, Mathisen KM, Milner JM, Skarpe C (2010a) Long-term browsing impact around diversionary feeding stations for moose in southern Norway. For Ecol Manag 259(10): 1900-1911

van Beest FM, Loe LE, Mysterud A, Milner JM (2010b) Comparative space use and habitat selection of moose around feeding stations. J Wildl Manag 74(2):219-227

Wang M, Grimm V (2007) Home range dynamics and population regulation: an individual-based model of the common shrew Sorex araneus. Ecol Model 205(3-4):397-409

Wollebæk A (1947) Classification appendix. In: Føyn B, Huus J (eds) Animals of Norway: mammals, vol 1. J.W. Cappelend Forlag, Oslo, pp 449-456

Ylönen H, Kojola T, Viitala J (1988) Changing female spacing behavior and demography in an enclosed breeding population of Cletrionomys glareolus. Holarct Ecol 11(4):286-292

Zuur AF, Ieno EN, Walker NL, Saveliev AA, Smith GM (2009) Mixed effects models and extensions in ecology with R. Springer, New York 